\title{
Potential of Coastal Water Bacteria for Oil Spill Bioremediation
}

\author{
Saif N. Al-Bahry, Asmaa Al-Hashmi, Sanket J. Joshi, Yahya M. Al-Wahaibi, \\ Abdulkadir E. Elshafie, and Ali S. Al-Bemani
}

\begin{abstract}
Around 30-40\% of global crude oil is exported from the Arabian Gulf via the Gulf of Oman, threatens marine species and leading to coastal pollution. Many natural ponds commonly found adjacent to the coast are prone to oil pollution. We isolated 50 bacteria from five natural pond sites and were identified using MALDI-Biotyper. Four isolates biodegraded crude oil in minimal salt medium are reported in this study. The selected microbial species were Actinocorallia, Klebsiella, Pseudomonas, and Rhizobium spp. This study indicated the potential of the microbes in bioremediation of oil spills.
\end{abstract}

\section{Keywords-Bacteria, bioremediation, crude oil, pollution}

\section{INTRODUCTION}

Petroleum hydrocarbons are the most widespread contaminants in marine and aquatic environments as a result of natural seepages and/or anthropogenic activities from ships, harbors, oil terminals and water run-off [1].

Light fractions of oil evaporates, photo-oxidizes or reacts with geo-chemicals while small portions of heavy fractions disperse in sediment, threatening aquatic biodiversity [2]. Many aquatic and marine microflora have been shown to play an important role in the biodegradation of oil spills by breaking down oil contaminants into nontoxic forms [3]. However, there is no single species that can entirely biodegrade complex form of hydrocarbons. More than 175 genera of bacteria were reported to use crude oil as a major carbon source of energy by producing biosurfactants, bioemulsifiers, enzymes and other metabolites [4]. However, no studies identifying bacteria capable of crude oil biodegradation were conducted in natural ponds of Oman.

The major objective of this investigation is to isolate and identify potential bacteria capable of crude oil biodegradation.

Manuscript received on December, $15^{\text {th }}, 2015$.

S .N. is in the Department of Biology, College of Science, Sultan Qaboos University, Oman.

A. A. is in the department of Biology, College of Science, Sultan Qaboos University, Oman.

S. J. is in the Central Analytical and Applied Research Unit, College of Science, Sultan Qaboos University.

Y. M. is the director of Oil and Gas Center, Sultan Qaboos University, Oman.

A. E. is in the Department of Biology, College of Science, Sultan Qaboos University, Oman.

A. B. is the Sultan Qaboos University Vice Chancellor Oman.

\section{Materials AND Methods}

Samples were collected from five sites of Seeb suburb in Muscat, Sultanate of Oman (Figure 1). The selected sites were from natural ponds a few meters away from the coast with exception of one site (site 4) which was a harbor for fishermen (Figure 1). Water and sludge samples were collected from each site in $50 \mathrm{~mL}$ sterile tubes and transferred immediately to the laboratory. The samples were inoculated in sterile minimal salt medium (MSM) containing: $1.8 \mathrm{~g} \mathrm{~K}_{2} \mathrm{HPO}_{4}, 4.0 \mathrm{~g} \mathrm{NH}_{4} \mathrm{Cl}, 0.2 \mathrm{~g}$, $\mathrm{MgSO}_{4} .7 \mathrm{H}_{2} \mathrm{O}$, 50g NaCl, 0.01g $\mathrm{FeSO}_{4} .7 \mathrm{H}_{2} \mathrm{O}$ per 1L [3] containing $1 \%$ crude oil as a carbon source and incubated in a shaking incubator $(160 \mathrm{rpm})$ for 7 days at $40{ }^{\circ} \mathrm{C}$. It was enriched for 5 days in the second set of MSM. The second step enrichment was conducted on MSM agar medium containing $1 \%$ crude oil and incubated in $40{ }^{\circ} \mathrm{C}$ for two days. Colonies forming clear zones were further selected in this study. Total of 50 cultures were identified by MALDI-TOF biotyper (Bruker MALDI Biotyper, CA System). Out of which four species were further selected in this study: Actinocorallia, Klebsiella, Pseudomonas and Rhizobium. Suspension cultures of the four microbes were further tested for crude oil biodegradation in a shaking incubator.

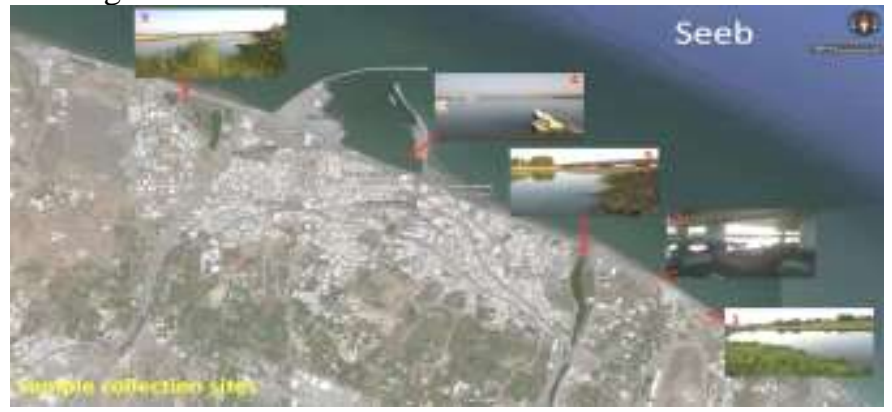

Fig. 1. Sample collection sites

The four isolated bacteria were inoculated in separate flasks containing $100 \mathrm{ml}$ MSM broth with $1 \%$ crude oil. The flasks were incubated at $40{ }^{\circ} \mathrm{C}$ in a shaker (160rpm) for 7 days. Then biodegraded crude oil was extracted with $n$-hexane in a separating funnel. The top layer of crude oil with hexane where collected and samples $(1 \mu \mathrm{L})$ were injected to the GC-FID and the fractions were analyzed by the FID detector at $400{ }^{\circ} \mathrm{C}$ where $\mathrm{H}_{2}$ flow $40 \mathrm{ml} / \mathrm{min}$, air flow $300 \mathrm{ml} / \mathrm{min}$ and $\mathrm{N}_{2}$ flow $15 \mathrm{ml} / \mathrm{min}$ were used as mobiles gases [5]. Crude oil degradation was recorded and compared with untreated crude oil. 
Hydrocarbon standards (C12 to C40) were used in GC-FID to determine concentration of each fraction in ppm and to obtain the percentage of degradation.

\section{RESUlTS \& DISCUSSION}

Flasks of MSM with $1 \%$ oil that were inoculated with samples showed degradation of oil layer at different rates among the flasks started on fourth day in some flasks while others on the fifth and sixth day of incubation. Some microbes in flasks emulsified the oil component. All flasks contents showed turbidity after 2 or 3 days of inoculation. Enrichment of those culture in another flask of same component for 5 days showed the same effects but in higher rate and shorter time in some flasks.

More than 50 colonies formed clear zones [6] on MSM plates with $1 \%$ crude oil were isolated and identified by MALDI Biotyper belonged to genera Actinocorallia, Comamonas, Halomonas, Klebsiella Pseudomonas, Rhizobium, and Staphylococcus. Four potential isolates (Actinocorallia, Klebsiella, Pseudomonas and Rhizobium) were reported in this study.

After 7 days of incubation, all four isolates showed significant degradation of crude oil (Figure 2). The four strains biotrasformed the heavier fractions of crude oil to lighter components. Most of the lighter fractions were not significantly degraded.

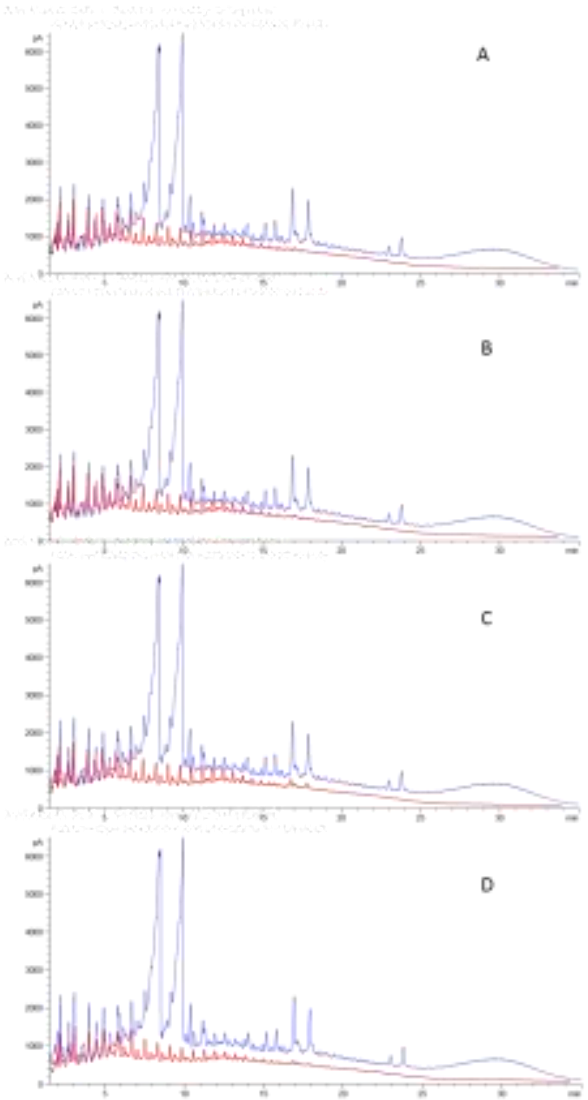

Fig. 2. GC-FID chromatographs for oil biodegradation by four isolates after 7 day incubation. $\mathrm{A}=$ Actinocorallia, $\mathrm{B}=$ Klebsiella $. \mathrm{C}=$ Pseudomona and $\mathrm{D}=$ Rhizobium, Blue spec $=$ control, red specs $=$ biodegraded crude oil.
The percentage of concentrations of each number of carbon chain was determined in the crude oil sample. The crude oil did not contain C21, C23, C30, C35, C36 and C37. The highest concentration was $\mathrm{C} 18$ with $13.4146 \%$, while the lowest was C38 hydrocarbon.

The four isolates showed different rates of crude oil fraction degradation as determined by their concentration percentages [7]. Pseudomonas exhibited maximum degradation, followed by Rhizobium (Figure 3). The minimum degradation was exhibited by Actinocorallia. In general, almost all strains revealed complete degradation of high carbon numbers. C14 was completely degraded by Klebsiella Pseudomonas, and Rhizobium species. C18, and C33 were completely degraded. C33 was biodegraded by Pseudomonas. Also, C36 was completely biodegraded by the three microbes except Klebsiella.
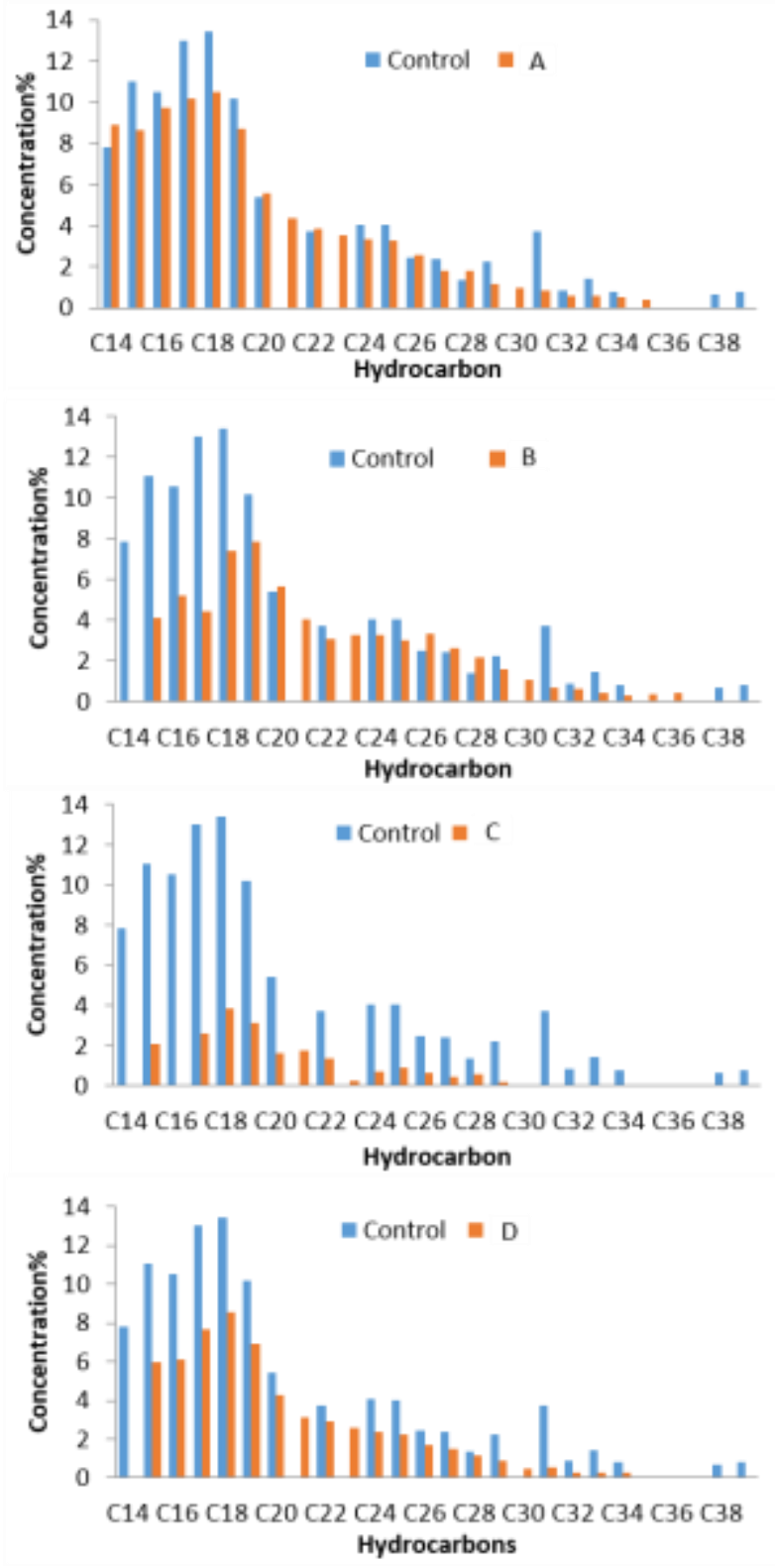

Fig. 3. Percentage hydrocarbon concentration of control compared to four isolates after 7 day incubation. $\mathrm{A}=$ Actinocorallia, $\mathrm{B}=$ Klebsiella $. \mathrm{C}=$ Pseudomonas and $\mathrm{D}=$ Rhizobium. 


\section{CONCLUSION}

Bacteria in natural ponds are adapted to biodegradation of pollutants. Such isolates could be used in environmental biotechnology to detoxify harmful pollutants in nature.

\section{ACKNOWLEDGMENT}

The authors wish to acknowledge the Central Analytical and Applied Research Unit at the Sultan Qaboos University for GC-FID analysis.

\section{REFERENCES}

[1] S. Muthuswamy, A. R. Binupriya, S. Baik, and S. Yun. 2008. "Biodegradation of Crude Oil by Individual Bacterial Strains and a Mixed Bacterial Consortium Isolated from Hydrocarbon Contaminated Areas." CLEAN - Soil, Air, Water 36 (1): 92-96. doi:10.1002/clen.200700042. http://dx.doi.org/10.1002/clen.200700042

[2] M. T. J., B. D. Folwell, B. A. McKew, and G. O. Sanni. 2012. "Marine Crude-Oil Biodegradation: A Central Role for Interspecies Interactions." Aquat. Biosyst 8 (10): 10-1186.

[3] M. A. Mohammed, A. Abd Hamid, A. Hamzah, and W. M. Wan Yusoff. 2008. "Development of Three Bacteria Consortium for the Bioremediation of Crude Petroleum-Oil in Contaminated Water." J. Biol. Sci 8 (4): 73-79.

[4] R.C. Prince, A. Gramain, T.J. McGenity: Prokaryotic hydrocarbon degraders. In Handbook of Hydrocarbon and Lipid Microbiology. Edited by Timmis KN, McGenity TJ, van der Meer JR, de Lorenzo V. Berlin Heidelberg: Springer; 2010:1671-1692 http://dx.doi.org/10.1007/978-3-540-77587-4_150

[5] A. Al-Sayegh, Y. Al-Wahaibi, S. Al-Bahry, A. Elshafie, A. Al-Bemani, and S. Joshi. 2015. "Microbial enhanced heavy crude oil recovery through biodegradation using bacterial isolates from an Omani oil field". Microbial cell factories, 14(1), p.141. http://dx.doi.org/10.1186/s12934-015-0330-5

[6] M. Udgire, N. Shah, and M. Jadhav. 2015. "Enrichment, Isolation and Identification of Hydrocarbon Degrading Bacteria." Int. J. Curr. Microbiol. App. Sci 4 (6): 708-13.

[7] Pi, Yongrui, Mutai Bao, Yiming Li, GuangmeiLi, Jinren Lu, and Peiyan Sun. 2015. "Characterization of crude oil Degrading Microbial Cultures Isolated in Qingdao China." RSC Adv. 5(118): 97665-74. doi: 10.1039\C5RA16628D 